\title{
Extradural Corticosteroid Injection in Management of Lumbar Nerve Root Compression
}

\author{
T. F. W. DILKE, H. C. BURRY, R. GRAHAME
}

British Medical fournal, 1973, 2, 635-637

\section{Summary}

The effect of extradural corticosteroid injection in patients with nerve root compression syndromes associated with degenerative disease of the lumbar intervertebral discs was assessed in a double-blind controlled trial on 100 consecutive inpatients assigned by random allocation to treatment and control groups. Assessment during admission and at three months revealed statistically highly significant differences in respect of relief of pain and resumption of normal occupation in favour of the group treated by extradural injection. This treatment seems to be a valuable adjunct to the management of lumbar nerve root compression syndromes associated with degenerative disc disease.

\section{Introduction}

That sciatic symptoms in degenerative lumbar disc disease may arise from the direct mechanical effect of pressure exerted by protruding disc material on nerve roots, and that such symptoms may therefore be relieved by surgical decompression of the nerve roots, has been widely accepted for nearly 40 years (Mixter and Barr, 1934; Mixter, 1937). There is, however, a good deal of evidence, both from operative and histological findings as well as from indirect sources (Falconer et al., 1948; Lindahl and Rexed, 1951; Kelly, 1956; Lindahl, 1966; Ito, 1971), which suggests that inflammatory changes present in and around affected nerve roots may also be of importance in the production of sciatic symptoms in lumbar disc disease. The possibility that, at least in some cases, these inflammatory changes could contribute significantly or even predominantly to the production and persistence of sciatic symptoms, has stimulated many attempts to treat sciatica by means of local antiinflammatory measures-in particular corticosteroid injections. Close proximity of the corticosteroid to the nerve root may be achieved by injecting it into the cerebrospinal fluid at segmental level (Lucherini, 1954), and reports have appeared (Cioffi and Giammusso, 1969; Gardner et al., 1961; Sehgal and Gardner, 1963) of many patients being treated for sciatica in this way, apparently with encouraging results. It has been suggested that corticosteroids introduced intrathecally would be too rapidly dispersed throughout the cerebrospinal fluid and extracellular fluid space to be able to exert an effective local anti-inflammatory action. However, it has been shown (Sehgal and Gardner, 1963; Fishman and Christy, 1965) that methylprednisolone suspension, unlike hydrocortisone acetate, may persist in the lumbar subarachnoid space for up to two or three weeks after injection. A number of cases have been reported (Roberts et al., 1967; Shealy, 1966; Dereux et al., 1956) of serious infective complications, including cases of tuberculous and cryptococcal menin-

Department of Rheumatology, Guy's Hospital, London SE1 9RT T. F. W. DILKE, B.M., M.R.C.P., Senior Registrar

H. C. BURRY, M.R.C.P., D.PHYS.MED., Consultant Rheumatologist

R. GRAHAME, M.D., M.R.C.P., Consultant Rheumatologist gitis, after intrathecal corticosteroid injection, and it would seem unsuitable for recommendation for routine use.

Injection into the extradural space affords an alternative method of bringing the corticosteroid into the immediate vicinity of the inflamed tissues (as may be shown by an extradurogram using contrast medium). The procedure is safe and simple, and could be widely adopted in the management of radiculitis associated with degenerative disc disease, if it were shown to be effective. Previous reports of the use of extradural corticosteroid injections in sciatica have been enthusiastic (Zappala, 1955; Fragasso, 1959; Goebert et al., 1961; Barry and Kendall, 1962; Canale, 1963; Lindholm and Salenius, 1964; Czarski, 1965; Harley, 1967; Swerdlow and Sayle-Creer, 1970; Gilly, 1970; Beliveau, 1971; Thurmand, 1972; Ito, 1971), but the absence of either a control series or sufficiently objective methods of assessment has detracted from the conviction they carry. The present study is an objective evaluation by means of a double-blind controlled clinical trial of the effect of extradural corticosteroid injection in the management of lumbar radicular compression syndromes.

\section{Method}

All the patients in the trial were admitted to hospital for treatment of unilateral sciatica due to lumbar disc disease. The criteria for admission to the trial were the presence of pain in the distribution of the sciatic or femoral nerves, accompanied by one or more of the following features: (1) painful limitation of sciatic or femoral nerve stretch, (2) sciatic scoliosis, and (3) an appropriate neurological deficit.

Grounds for exclusion were diagnostic uncertainty, bilateral manifestations, previous surgery to the lumbar spine, coincident medical conditions affecting rehabilitation, and any doubt about the technical success of an injection.

Altogether, 100 consecutive patients satisfying these criteria and consenting to take part in the trial were allocated at random to "treated" and "control" groups. Those in the treated group received as part of their initial treatment on admission an extradural injection of $80 \mathrm{mg}$ of methylprednisolone in $10 \mathrm{ml}$ normal saline, given by the lumbar route as described by Barry and Kendall (1962). Those in the control group received a superficial injection into the interspinous ligament of $1 \mathrm{ml}$ of normal saline, preliminary local anaesthesia being given in all cases. All injections were performed by the same person, and neither the patient, the clinician in charge of the case, nor any staff concerned in subsequent assessments or management knew which type of injection had been gien. Analgesics were offered four times a day, mefenamic acid being used routinely. Diazepam, a drug with acknowledged skeletal muscle relaxant properties, was prescribed for all patients in a dose of $2 \mathrm{mg}$ three times daily.

After an initial period of bed rest, all patients received a routine programme of graded rehabilitation, which comprised hydrotherapy and postural exercise classes (Kendall and Jenkins, 1968), and later spinal mobilizing exercises. Decisions regarding the timing of these stages, the length of hospital stay, resumption of work, and the necessity for additional forms of treatment or for referral for surgery were made by the clinician in charge of the case, who remained unaware of the type of injection given.

Previous experience has suggested that a second extradural injection, given a few days or a week after the first, may be 
successful when there has been a negative or partial response to the first, whereas a third injection is rarely helpful. Provision was therefore made in this trial for a second injection of the same type as the first to be given at a week's interval if the clinician in charge felt that progress had been unsatisfactory.

\section{ASSESSMENT}

Assessment of progress was made by consideration of the following points.

\section{Duration of Incapacity}

(a) Duration of complete bed rest in hospital. (b) Time interval between admission to hospital and institution of spinal mobilizing exercises. (c) Duration of hospital admission. (d) Time interval between admission to hospital and resumption of normal occupation.

\section{Relief of Pain}

(a) Analgesic consumption while in hospital. The total number of occasions on which analgesic tablets were required was calculated for each week of the hospital admission. Each weekly total was divided by seven to provide a daily "pain score" calculated to the nearest half. Three groups were defined: (1) where the pain score decreased by two or more between the first and third weeks ("Pain clearly relieved"); (2) where the pain score decreased by one or less or actually increased during the entire hospital stay ("Pain clearly not relieved"); and (3) an intermediate group.

(b) Analgesic consumption at the time of the three-month assessment, classified as none, less than daily, and every day.

(c) Patients' assessment of pain at three month follow-up, classified as severe, not severe, and none.

\section{Clinical Signs}

(a) Changes in angle of straight leg raising. Four arbitrary groups were defined: (1) angle on affected side improved by $30^{\circ}$ or more in the first week; (2) straight leg raising became equal on the two sides during admission; (3) angle on affected side improved by more than $20^{\circ}$ during admission; and (4) no change or worse.

(b) Changes in neurological signs, assessed at discharge from hospital and at three months after admission, and classified as abolished, unchanged, and intermediate.

\section{Other Treatment Prescribed}

(a) Second injection.

(b) Other conservative treatment (this included lumbar support or plaster of Paris jacket, traction, outpatient physiotherapy after discharge, local corticosteroid infiltration of painful areas, and readmission).

(c) Referral for surgery.

\section{COMPARABILITY OF THE GROUPS}

The two groups of patients were analysed with respect to age, sex distribution, incidence of neurological deficit, presence of impulse pain (sciatic pain felt on coughing, sneezing, laughing, etc.), presence of sciatic scoliosis, previous history of sciatica, radiological abnormalities of the lumbosacral spine, and occupation. This last factor was assessed ergonomically by the Department of Community Medicine in terms of the effort, postures, and amount of bending required in carrying out the day's work. The results of these analyses (table I) show that there
TABLE I-Comparability of Groups

\begin{tabular}{|c|c|c|c|c|c|c|}
\hline & & & & & Treated & Control \\
\hline \multicolumn{2}{|c|}{$\begin{array}{l}\text { Average age in years (range) } \\
\text { Sex: }\end{array}$} & . & .. & .. & $38 \cdot 7(18-75)$ & $42 \cdot 3(18-66)$ \\
\hline Males $\ldots \quad \ldots$ & .. & $\cdots$ & .. & . & \multirow{6}{*}{$\begin{array}{l}27(53 \%) \\
24(47 \%) \\
40(78 \%) \\
37(73 \%) \\
35(69 \%) \\
13(26 \%)\end{array}$} & \multirow{6}{*}{$\begin{array}{l}28(58 \%) \\
20(42 \%) \\
37(77 \%) \\
31(65 \%) \\
30(63 \%) \\
17(35 \%)\end{array}$} \\
\hline Females. & .. & .. & .. & . & & \\
\hline Neurological deficit & .. & . & . & . & & \\
\hline Impulse pain $\quad$. & . & . & .. & .. & & \\
\hline $\begin{array}{l}\text { Sciatic scoliosis } \\
\text { Previous history of sciat }\end{array}$ & & $\cdots$ & . & $\cdots$ & & \\
\hline$X$-ray appearances of lu & mbar s & ine: & & $\cdots$ & & \\
\hline Normal $\quad$. & . & . & . & . & \multirow{3}{*}{$\begin{array}{l}17(33 \%) \\
27(53 \%) \\
11(22 \%)\end{array}$} & \multirow{3}{*}{$\begin{array}{l}12(25 \%) \\
28(58 \%) \\
19(40 \%)\end{array}$} \\
\hline $\begin{array}{l}\text { Disc space narrowing } \\
\text { Degenerative changes }\end{array}$ & & $\because$ & $\because$ & $\because$ & & \\
\hline Duration of symptoms: & & & & & & \\
\hline $\begin{array}{l}1-4 \text { weeks } \\
4 \text { weeks- } 3 \text { months }\end{array}$ & $\because$ & $\because$ & . & $\because$ & \multirow{5}{*}{$\begin{array}{r}5 \\
13 \\
17 \\
10 \\
5 \\
0\end{array}$} & \multirow{5}{*}{$\begin{array}{r}5 \\
14 \\
16 \\
7 \\
5 \\
2\end{array}$} \\
\hline 3-6 months .. & $\because$ & $\because$ & . & $\because$ & & \\
\hline 6 months-1 year & .. & .. & .. & . & & \\
\hline 1-2 years $\quad \cdots$ & $\cdots$ & $\cdots$ & . & $\cdots$ & & \\
\hline $\begin{array}{l}\text { Over } 2 \text { years } \quad \cdots \\
\text { Occupation: }\end{array}$ & $\cdots$ & . & . & $\cdots$ & & \\
\hline $\begin{array}{l}\text { Effort } \\
\text { Posture ... } \\
\text { Stooping }\end{array}$ & . & . & ․ & \} & No significan & lifference found \\
\hline
\end{tabular}

was no significant difference between the two groups in respect of any of these factors. Spinal degenerative changes and a previous history of sciatica were rather more common in the control group, but impulse pain, the presence of which has been shown in a previous study (J. E. Davies and H. C. Burry, 1970, unpublished observation) to be an adverse prognostic factor in sciatica, was more common in the treated group.

\section{Results}

An analysis of the results is shown in tables II, III, and IV.

TABLE II-Duration of Incapacity after Admission

\begin{tabular}{|c|c|c|c|}
\hline & Treated & Control & Significance \\
\hline Time on full bed rest (days) & $8 \cdot 25$ & $8 \cdot 61$ & N.S. \\
\hline $\begin{array}{l}\text { Time to institution of spinal mobil- } \\
\text { izing exercises (days) }\end{array}$ & $18 \cdot 4$ & $20 \cdot 4$ & N.S. \\
\hline Time in hospital (days) & $25 \cdot 2$ & $28 \cdot 0$ & N.S. \\
\hline $\begin{array}{l}\text { Resumption of work }:^{*} \\
\text { Not resumed at three months } \\
\text { Time to resumption in remainder } \\
\text { (weeks) }\end{array}$ & 3 of 36 & 14 of 35 & $\begin{array}{c}0.01<\underset{x^{2}}{=}=9.43 \\
\text { N.S. }\end{array}$ \\
\hline
\end{tabular}

*After exclusion of 17 surgical cases, nine in whom it was not known, and two who were made redundant.

TABLE III-Relief of Pain

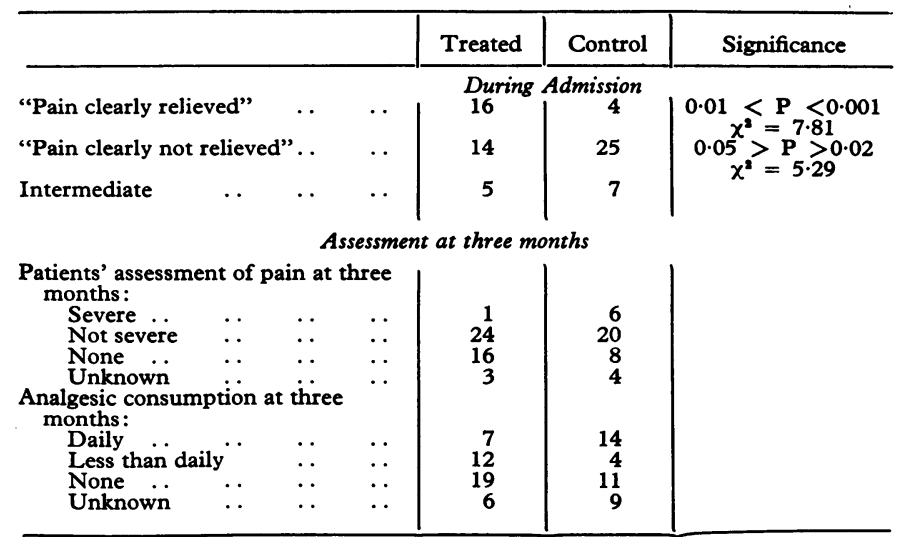


TABLE IV-Other Treatment Prescribed

\begin{tabular}{|c|c|c|c|c|c|}
\hline & & & Treated & Control & Significance \\
\hline Surgery & . & .. & $7(13.7 \%)$ & $10(20 \cdot 8 \%)$ & N.S. \\
\hline Second Injection & $\ldots$ & . & $16(31 \cdot 4 \%)$ & $23(47 \cdot 9 \%)$ & N.S. \\
\hline Other non-surgical & . & . & $9(17 \cdot 6 \%)$ & $14(29 \cdot 1 \%)$ & N.S. \\
\hline
\end{tabular}

The most striking result relates to resumption of usual occupation as assessed at three months from the date of admission. Fourteen patients from the control group had not resumed work compared with only three from the treated group, a difference which is significant at the $1 \%$ level. Furthermore, the treated patients showed a statistically highly significant decrease in analgesic requirement during admissions compared with the control group, suggesting that the extradural injection had provided early relief of symptoms. In addition, only one treated patient complained of severe pain at three months compared with six of the control subjects, whereas a report of no pain at three months was twice as common in the treated patients as in the controls; and a similar pattern is apparent from analysis of the analgesic consumption at three months. Referrals for surgery were also less common in the treated group, and fewer required second injections or other forms of conservative treatment, though the results for these parameters did not reach statistical significance. The analyses of changes in the range of straight leg raising and neurological deficits (not tabulated) showed no significant difference between the two groups of patients.

\section{COMPLICATIONS}

There were no complications attributable to the injections. A minority of patients experience transient pain of sciatic distribution during extradural injection, which may be reduced by slowing the rate of injection. Cerebrospinal fluid was inadvertently tapped on six occasions in the course of this trial, and when this happened the needle was withdrawn and an extradural injection was carried out immediately through an adjacent interspinous space. Several thousand extradural corticosteroid injections have been carried out in this department, and our findings are in agreement with those of other workers-that the procedure is entirely safe, provided careful attention to asepsis is observed.

\section{Discussion}

In assessing the significance of these results, it should be borne in mind that the patients admitted to this trial will have included a group in whom early resolution of symptoms would naturally occur during a two-week period of bed rest in hospital, and conversely a group in whom the mechanical pressure exerted by the disc prolapse on the nerve root would be of such severity as to make surgery inevitable. It is likely that the presence of these two groups influenced the overall results and prevented some trends in favour of the treated group from reaching statistical significance. Nevertheless, the trial did reveal a significant difference in favour of the treated group in respect of two important parameters, one reflecting pain and the other reflecting disability. In the case of referrals for surgery, referrals for second injections, and other conservative measures, the numbers concerned were small and a larger series might well have shown a significant result.

In view of the undoubted relief of pain and earlier resumption of normal occupation in the treated group, it is at first sight surprising that measurable improvements in neurological deficits and nerve stretch tests were not found. These measurements are, however, subject to inter and intraobserver differences in patients with painful radicular syndromes, and are hard to quantify in a reproducible fashion. Furthermore, where radicular damage is greater than neurapraxic, recovery cannot be expected in a short-term follow-up.

The small differences found in respect of the duration of the various stages of rehabilitation may be explained by the tendency to assume that patients with the same condition will get better at about the same rate, leading to a bias towards uniformity in the ordering of the progress through these various stages.

The mechanism of the effect of extradural injections in sciatica has been the subject of debate. Before the advent of corticosteroids there was a tendency to use large volumes of fluid (up to $200 \mathrm{ml}$ ), and Evans (1930) reported that the factor determining success was not the composition of the fluid injected but its volume, which he felt should exceed $60 \mathrm{ml}$. The putative mechanism was a "fluid dissection" of the extradural space, freeing the nerve root from the extruded disc material, or breaking down peridural adhesions. An explanation of this sort would perhaps account for the immediate relief of pain reported in some of his cases by Evans and noted also by other workers. With the technique used in the present study it is unlikely that this mechanical explanation would apply, and the results are rather to be attributed to the anti-inflammatory effect of the steroid. The time course of the improvement after injection, which is not immediate but occurs gradually over one to four days, is in accordance with this explanation.

We wish to thank the staff of the Hume Kendall Unit at New Cross Hospital for their co-operation throughout this study. We wish also to acknowledge our debt to Dr. M. E. Abrams, of the Department of Medicine, Guy's Hospital, and Dr. J. A. D. Anderson, of the Department of Community Medicine, Guy's Hospital, for helpful advice and discussions.

\section{References}

Barry, P. J. C., and Kendall, P. H. (1962). Annals of Physical Medicine, 6, 267.

Beliveau, P. (1971). Rheumatology and Physical Medicine, 11, 40.

Canale, L. (1963). Gazzetta Medica Italiana, 122, 210.

Cioffi, F. A., and Giammusso, V. (1969). Rassegna Internazionale di Clinica e Terapia, 49, 840.

Czarski, Z. (1965). Przeglad Lekarski, 21, 511.

Dereux, J., Vandenhaute, A., and Deheck, M. (1956). Revue Neurologique, 94, 301 .

Evans, W. (1930). Lancet, 2, 1225.

Falconer, M. A., McGeorge, M., and Begg, A. C. (1948). Fournal of Neurology, Neurosurgery, and Psychiatry, 11, 13.

Fishman, R. A., and Christy, N. P. (1965). Neurology, 15, 1.

Fragasso, V. (1959). Gazzetta Medica Italiana, 118, 358

Gardner, W. J., Goebert, H. W., and Sehgal, A. D. (1961). Transactions of the American Neurological Association, 86, 214.

Gilly, R. (1970). Marseille médical. 107, 341.

Goebert, H. W., Jallo, S. J., Gardner, W. J., and Wasmuth, C. E. (1961). Current Research in Analgesia and Anaesthesia, 40, 130.

Current Research in Analgesia and Anaesthesia, 40,
Harley, C. (1967). Annals of Physical Medicine, 9, 22.

Harley, C. (1967). Annals of Physical Medicine, 9, 22.

Kelly, M. (1956). Neurology, 6, 32.

Kendall, P. H., and Jenkins, J. M. (1968). Physiotherapy, 54, 158

Lindahl, O., and Rexed, B. (1951). Acta Orthopaedica Scandinavica, 20, 215 Lindahl, O. (1966). Acta Orthopaedica Scandinavica, 37, 367.

Lindholm, R., and Salenius, P. (1964). Acta Orthopaedica Scandinavica, 34, 114.

Lucherini, T. (1954). Policlinico, Sezione Pratica, 29, 841.

Mixter, W. J., and Barr, J. S. (1934). New England fournal of Medicine, 211, 210.

Mixter, W. J. (1937). Annals of Surgery, 106, 777.

Roberts, M., Sheppard, G. L., and McCormick, R. C. (1967). Fournal of the American Medical Association, 200, 894.

Sehgal, A. D., and Gardner, W. J. (1963). Transactions of the American Neurological Association, 88, 275 .

Shealy, C. N. (1966). Fournal of the American Medical Association, 197, 1104.

Shealy, C. N. (1966). Fournal of the American Medical Association,
Swerdlow, M., and Sayle-Creer, W. (1970). Anaesthesia, 25, 341.

Swerdlow, M., and Sayle-Creer, W. (1970). Anaesthesia,

Zappala, G. (1955). Policlinico, Sezione Pratica, 37, 1229. 